\title{
Risk factors for systemic and venous thromboembolism, mortality and bleeding risks in 1125 patients with COVID-19: relationship with anticoagulation status
}

\author{
Wencheng $\mathrm{Li}^{1}$, Zhifeng $\mathrm{Xu}^{2}$, Huiling Xiang ${ }^{2}$, Chun Zhang ${ }^{2}$, Yutao Guo ${ }^{3,4,}{ }^{*}$, Jing Xiong ${ }^{2, *}$ \\ ${ }^{1}$ Department of Urology, Union Hospital, Tongji Medical College, Huazhong University of Science and Technology, \\ Wuhan 430022, China \\ ${ }^{2}$ Department of Nephrology, Union Hospital, Tongji Medical College, Huazhong University of Science and \\ Technology, Wuhan 430022, China \\ ${ }^{3}$ Medical School of Chinese PLA, Department of Cardiology, Chinese PLA General Hospital, Beijing 100853, \\ China \\ ${ }^{4}$ Liverpool Centre for Cardiovascular Sciences, University of Liverpool and Liverpool Heart and Chest Hospital, \\ Liverpool L69 3BX, United Kingdom \\ *Co-senior authors
}

Correspondence to: Jing Xiong, Yutao Guo; email: jingxiong@hust.edu.cn, guoyutao@301hospital.com.cn Keywords: COVID-19, thromboembolism, bleeding, death

Received: December 3, 2020 Accepted: February 3, 2021

Published: March 26, 2021

Copyright: (C) $2021 \mathrm{Li}$ et al. This is an open access article distributed under the terms of the Creative Commons Attribution License (CC BY 3.0), which permits unrestricted use, distribution, and reproduction in any medium, provided the original author and source are credited.

\section{ABSTRACT}

Aim: Coronavirus disease 2019 (COVID-19) has been associated with increased mortality and morbidity from thromboembolism, especially venous thromboembolism. There are more limited data for systemic thromboembolism. The present study aimed to investigate the prevalence of systemic and venous thromboembolism as well as major bleeding and mortality in relation to underlying risk factors and the impact of anticoagulation use in hospitalized patients with COVID-19.

Methods and results: Patients with COVID-19 admitted to Union Hospital, Wuhan, Hubei, China between January 08, 2020 and April 7, 2020 were enrolled in this retrospective study. Cox proportional hazard models were utilized to determine associated risk factors for clinical events, adjusting for the severity of COVID-19 infection, drug therapies, comorbidities, surgery, and use of antithrombotic drugs.

There were 1125 patients (49.9\% male; mean age 58 years (standard deviation, SD, 15 years)) with a mean follow-up of 21 (SD 13) days. Approximately 25 (30\%) patients with thromboembolism also suffered bleeding events.

Age was an independent risk factor for thromboembolism, bleeding events, and death (all p<0.05). After adjusting for the severity of COVID-19 infection, comorbidities, surgery, antiviral drugs, immunomodulators, Chinese herbs, and antithrombotic drugs, low lymphocyte counts (hazard ratio, HR, 95\% confidence interval (CI), 1.03, 1.01-1.05, $p=0.01$ ) and surgery (HR 2.80, 1.08-7.29, $p=0.03$ ) independently predicted the risk for major bleeding, whereas liver dysfunction (HR 4.13, 1.30-13.1, $p=0.02$ ) was an independent risk factor for patients with both thromboembolism and bleeding events.

Conclusions: Patients with COVID-19 were at high risk for thromboembolic and bleeding events as well as mortality. The use of anticoagulants, especially parenteral anticoagulants, significantly reduced the risk for composite outcomes of thromboembolism, bleeding events, and death. The presence of AF was a contributor to systemic thromboembolism in COVID-19 patients. 


\section{INTRODUCTION}

The coronavirus disease 2019 (COVID-19) pandemic has resulted in approximately 3 million infections globally, with over 200,000 deaths, mainly due to severe acute respiratory syndrome and multiorgan dysfunction [1]. In studies conducted during the early stage of the COVID-19 outbreak, various hemostatic abnormalities were reported, including thrombocytopenia, prolongation of prothrombin time, international normalized ratio and thrombin time, elevated D-dimer levels, etc. [2-6]. Increased mortality and morbidity from thromboembolism, especially venous thromboembolism, have been reported, commonly in critically ill COVID-19 patients [7-9]. These acute thromboembolic events were strongly associated with worsening outcomes, highlighting the necessity for thromboembolism risk management [10].

Despite the data on venous thromboembolism in COVID-19, there are more limited data on systemic thromboembolism and the value of anticoagulation regimens in balancing the risks of major bleeding. One study showed that anticoagulants reduced mortality in COVID-19 patients with D-dimer > 3.0 $\mu \mathrm{g} / \mathrm{mL}$ [11], but there appear to be empiric therapeutic anticoagulation approaches in current practice. The appropriate choice of anticoagulant type, together with the appropriate dosages for thromboprophylaxis, remains unclear in the absence of published randomized trials. For example, intermediate-dosage low-molecularweight heparin (LMWH) thromboprophylaxis (40-60 $\mathrm{mg}$ ) is commonly used in Chinese patients [11], whereas higher dosages (i.e., $80-100 \mathrm{mg}$ ) are considered in Italy [12].

High thromboembolism risks have been reported in severely or critically ill patients, but there are fewer data in relation to underlying risk factors and the impact of anticoagulation use in patients with COVID-19 on systemic and venous thromboembolism separately as well as on major bleeding and mortality. Indeed, there are complex interactive factors that could impact both thromboembolic and bleeding risks that would influence decision making, including the severity of COVID-19 infection, comorbidities, surgery or interventional procedures, drug therapies, and the use of antithrombotic drugs.

In the present study, our aim was to investigate the prevalence of systemic and venous thromboembolism as well as major bleeding and mortality in relation to underlying risk factors and the impact of anticoagulation use among hospitalized patients with COVID-19.

\section{RESULTS}

We included 1,125 patients (561, 49.9\% male; mean age 58 (SD 15) years, range 14-97 years) with a mean followup of 21 (SD 13) days (Table 1). Of them, 408 (36.3\%) were aged over 65 years, and 33 (2.9\%) underwent surgery; admission specialties are summarized in Supplementary Table 1. The average duration of symptoms to hospital admission was 17 days (SD 11). Hypertension, diabetes mellitus, and coronary artery disease were the most common comorbidities in this population (Table 1). Antiviral drugs were used by the admitting team in $788(70.0 \%)$ patients, and glucocorticoid drugs were used in $203(18.0 \%)$ patients. Anticoagulants were used in $249(22.1 \%)$ patients: 87 $(7.7 \%)$ oral anticoagulants, $209(18.6 \%)$ parenteral anticoagulants (intermediate dose LMWH, or intravenous heparin), and 47 (4.2\%) were prescribed both oral anticoagulants plus parenteral anticoagulants (Table 2).

\section{Clinical outcomes}

There were $82(7.3 \%)$ thromboembolic events (deep vein thrombosis in $42(3.7 \%)$, pulmonary embolism in 3 $(0.3 \%)$, and ischemic stroke in $37(3.3 \%)$ patients) and major bleeding events in $128(11.4 \%)$ patients (Table 3). Approximately 25 (30\%) patients with thromboembolism also suffered bleeding events (Table 3). All-cause death occurred in $91(8.1 \%)$ patients.

Age was an independent risk factor for thromboembolism, bleeding events, and death, both individually and in combination (all $\mathrm{p}<0.05$, Figure $1 \mathrm{~A}-1 \mathrm{E}$ and Supplementary Tables 2, 3, 4).

In univariate analyses, hypertension, AF/irregular rhythm, heart failure, peripheral artery disease, cancer, obstructive sleep apnea syndrome, and renal dysfunction were associated with an increased risk for thromboembolism, whereas antiviral and antithrombotic treatment reduced the risk (all $\mathrm{p}<0.05$, Figure $1 \mathrm{~A}$ and Supplementary Table 2A).

After adjusting for the severity of COVID-19 infection, comorbidities, surgery, antiviral drugs, immunomodulators, Chinese herbs and antithrombotic drugs, the use of oral anticoagulants (HR 0.32, 0.190.53 ) and parenteral anticoagulants (HR 0.39, 0.220.70) reduced the risk for thromboembolism (all $\mathrm{p}<0.001$, Figure 1A), as did antiviral drugs.

The presence of low lymphocyte counts (HR 1.03, 1.01$1.05, \mathrm{p}=0.01$ ) and surgery (HR 2.80, 1.08-7.29, $\mathrm{p}=0.03$ ) independently predicted the risk for major bleeding, as did parenteral anticoagulants (HR 1.56, 1.01-2.42, $\mathrm{p}=0.04$ ) (Figure 1B and Supplementary Table 2B). 
Table 1. Baseline characteristics of 1125 patients with COVID-19.

\begin{tabular}{|c|c|}
\hline & Patients $(n=1125)$ \\
\hline Age, mean, SD & $58.3(15.1)$ \\
\hline Age $\leq 17$ & $3(0.3)$ \\
\hline Age 18-64 & $714(63.5)$ \\
\hline Age 65-74 & $268(23.8)$ \\
\hline Age $75-84$ & $102(9.1)$ \\
\hline Age $\geq 85$ & $38(3.4)$ \\
\hline Male, n (\%) & $561(49.9)$ \\
\hline Days to admission, mean, SD & $17.1(11.5)$ \\
\hline Respiratory rate (time/minute), mean, SD & $22(4)$ \\
\hline Heart rate (time/minute), mean, SD) & $91(27)$ \\
\hline \multicolumn{2}{|l|}{ Blood test } \\
\hline White blood cell $\left(10^{9} / \mathrm{L}\right)$, mean, SD & $6.8(3.7)$ \\
\hline Platelet $\left(10^{9} / \mathrm{L}\right)$, mean, SD & $225.3(90.4)$ \\
\hline Leucocyte $(\%)$, mean, SD & $22(16)$ \\
\hline \multicolumn{2}{|l|}{ Comorbidities } \\
\hline Hypertension, n (\%) & $367(32.6)$ \\
\hline Diabetes mellitus, n (\%) & $204(18.1)$ \\
\hline Lipid disorder, n (\%) & $180(16)$ \\
\hline Coronary artery disease, $\mathrm{n}(\%)$ & $103(9.2)$ \\
\hline Liver dysfunction*, n (\%) & $65(5.8)$ \\
\hline Cancer, n (\%) & $65(5.8)$ \\
\hline AF/irregular rhythm*, n (\%) & $62(5.5)$ \\
\hline Bleeding diathesis*, n $(\%)$ & $43(3.8 \%)$ \\
\hline Peripheral artery disease, $\mathrm{n}(\%)$ & $36(3.2)$ \\
\hline Heart failure, n (\%) & $32(2.8)$ \\
\hline Renal dysfunction*, n (\%) & $27(2.4)$ \\
\hline Hypertrophic cardiomyopathy, n (\%) & $23(2.0)$ \\
\hline Obstructive sleep apnea syndrome, n (\%) & $19(1.7)$ \\
\hline Hyperthyroidism, n (\%) & $4(0.4)$ \\
\hline Surgery, n (\%) & $33(2.9)$ \\
\hline Obstetrics and gynecology operation*, n (\%) & $22(2.0)$ \\
\hline General surgical operation*, n (\%) & $5(0.4)$ \\
\hline Orthopedic surgery*, n (\%) & $4(0.4)$ \\
\hline Neurosurgery* ${ }^{*}, \mathrm{n}(\%)$ & $2(0.2)$ \\
\hline \multicolumn{2}{|l|}{ Combined drugs } \\
\hline Calcium channel blockers, n (\%) & $227(20.2)$ \\
\hline Anti-acid drugs, n (\%) & $218(19.4)$ \\
\hline 6 blockers, n (\%) & $172(15.3)$ \\
\hline Statins, n (\%) & $139(12.4)$ \\
\hline Insulin, n (\%) & $131(11.6)$ \\
\hline ACEI/ARB*, n $(\%)$ & $96(8.5)$ \\
\hline Nitrates, n (\%) & $80(7.1)$ \\
\hline$\alpha$-glucosidase inhibitor, $\mathrm{n}(\%)$ & $77(6.8)$ \\
\hline Biguanide, n (\%) & $68(6.0)$ \\
\hline Diuretics, n (\%) & $59(5.2)$ \\
\hline Spirolactone, n (\%) & $29(2.6)$ \\
\hline Sulfonylureas, n (\%) & $17(1.5)$ \\
\hline Digoxin, n (\%) & $10(0.9)$ \\
\hline Amiodarone, n (\%) & $3(0.3)$ \\
\hline
\end{tabular}




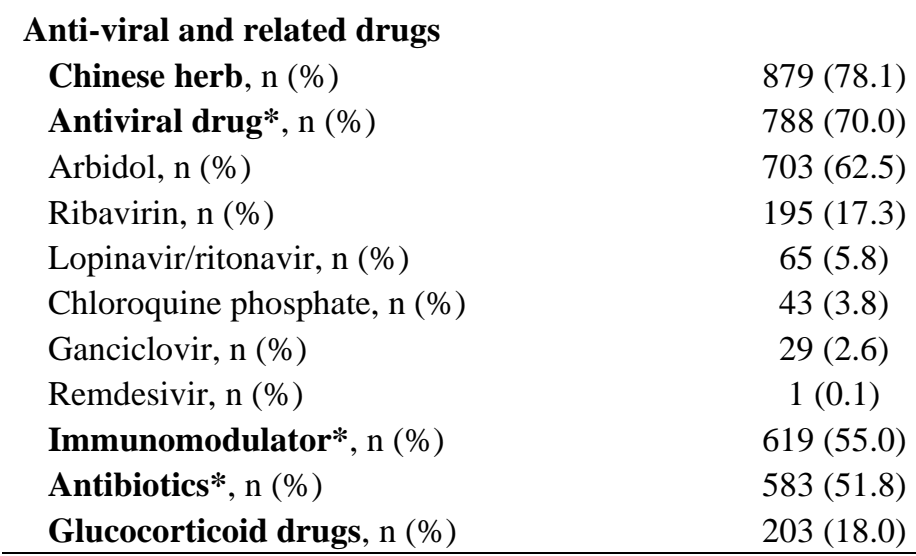

*For definitions of liver and renal dysfunction, lipid disorder, bleeding diathesis, see text.

Obstetrics and gynecology operations: midwifery, cesarean delivery, dilatation and curettage, oophorocystectomy. General surgical operations: appendectomy, interventional embolization of gastric varices, laparocolectomy. Orthopedic surgery: hip disarticulation, open reduction and internal fixation, hollow screw fixation. Neurosurgery: extraventricular drainage, minimally invasive drilling and drainage of subdural hematoma.

ACEI/ARB: angiotensin-converting enzyme inhibitor/angiotensin II receptor blocker.

Immunomodulator: interleukin-2, interferon, immunoglobulin, thymopentin.

Antibiotics: ceftizoxime sodium, ceftriaxone sodium, cefprozil, cefzon, ceftazidime, cefoperazone sodium sulbactam sodium, meropenem trihydrate, azithromycin, clarithromycin, levofloxacin, moxifloxacin, ornidazole, metronidazole, vancomycin, linezolid, teicoplanin.

There were 250 patients who received two antiviral drugs in sequence.

Table 2. Antithrombotic treatment in patients with COVID-2019.

\begin{tabular}{lc}
\hline & Patients (n=1125) \\
\hline Total Anticoagulants, $\mathrm{n}(\%)$ & $\mathbf{2 4 9}(\mathbf{2 2 . 1})$ \\
Oral anticoagulants, $\mathrm{n}(\%)$ & $\mathbf{8 7}(\mathbf{7 . 7 )}$ \\
NOAC*, n (\%) & $82(7.3)$ \\
Warfarin, n (\%) & $5(0.4)$ \\
Parenteral anticoagulants, $\mathrm{n}(\%)$ & $\mathbf{2 0 9}(\mathbf{1 8 . 6})$ \\
LMWH*, n (\%) & $111(9.9)$ \\
Heparin, n (\%) & $103(9.2)$ \\
Oral anticoagulants plus & $\mathbf{4 7}(\mathbf{4 . 2})$ \\
parenteral anticoagulants, $\mathbf{n}(\%)$ & $\mathbf{1 0 6}(\mathbf{9 . 4})$ \\
Total antiplatelets, $\mathrm{n}(\%)$ & $77(6.8)$ \\
Aspirin, n (\%) & $49(4.4)$ \\
Clopidogrel, n (\%) & $1(0.1)$ \\
Others, n (\%) &
\end{tabular}

* NOAC: non-vitamin K antagonist oral anticoagulant, rivaroxaban or dabigatran. LMWH: low molecular weight heparin. There were 21 patients with dual antiplatelet (aspirin plus clopidogrel); 5 patients who received both heparin and LMWH. 
Table 3. Thromboembolism and bleeding events during hospitalization.

\begin{tabular}{lc}
\hline & Patients (n=1125) \\
\hline Thromboembolism, $\mathrm{n}(\%)$ & $82(7.3)$ \\
Deep vein thromboembolism, $\mathrm{n}(\%)$ & $42(3.7)$ \\
Ischaemic stroke, $\mathrm{n}(\%)$ & $37(3.3)$ \\
Pulmonary thromboembolism, $\mathrm{n}(\%)$ & $3(0.3)$ \\
Bleeding events*, n (\%) & $128(11.4)$ \\
Gastrointestinal bleeds, $\mathrm{n}(\%)$ & $18(1.6)$ \\
Intracranial haemorrhage, $\mathrm{n}(\%)$ & $6(0.5)$ \\
Major bleeding*, $\mathrm{n}(\%)$ & $113(10.0)$ \\
Thromboembolism and bleeding events, $\mathrm{n}(\%)$ & $25(2.2)$ \\
\hline
\end{tabular}

* Major bleeding was defined as a drop of $\mathrm{Hg} \geq 2 \mathrm{~g} / \mathrm{L}$, or needed the infusion of $\mathrm{RBC} \geq 2$ unit. Bleeding events: included gastrointestinal bleeds, intracranial haemorrhage, and major bleeding.

A

Thromboembolism

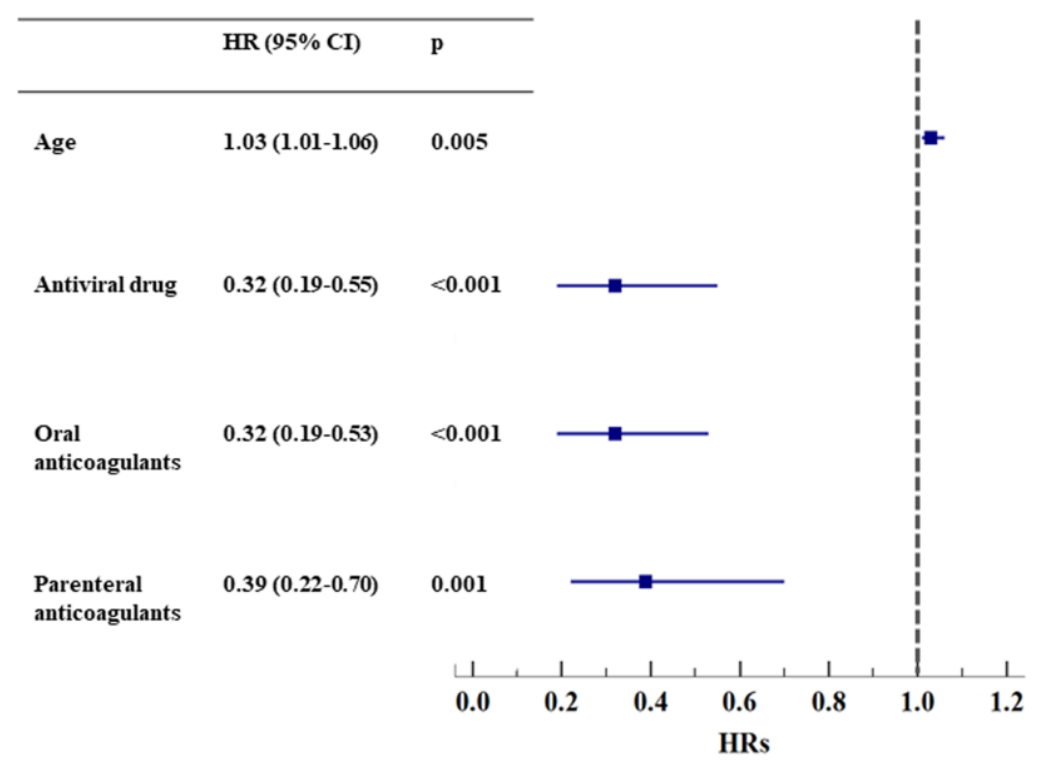

B

Major bleeding

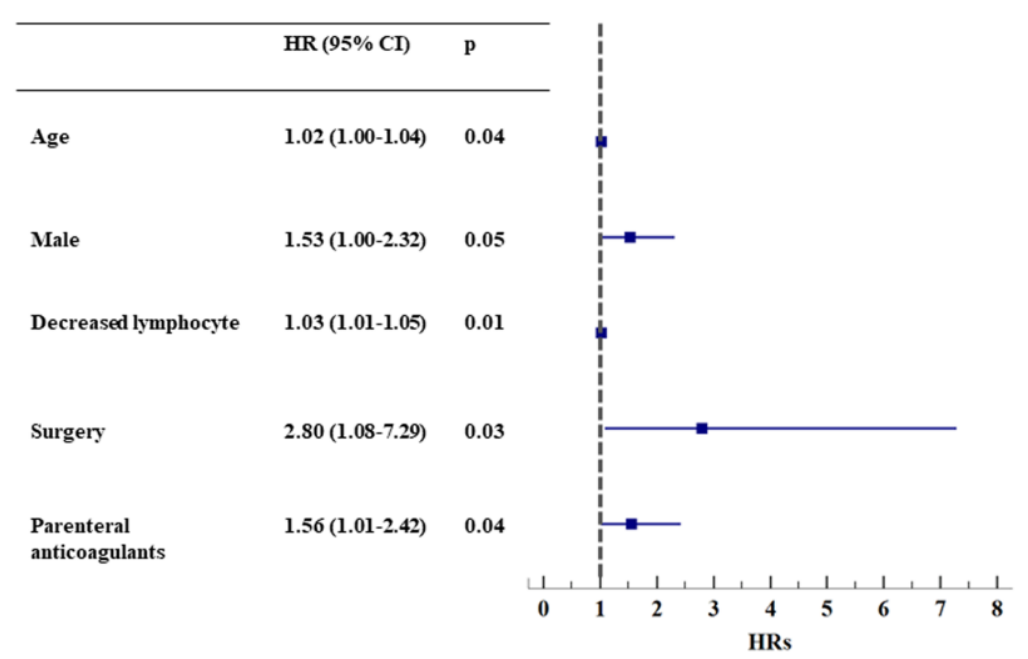


C

Thromboembolism and bleeding events

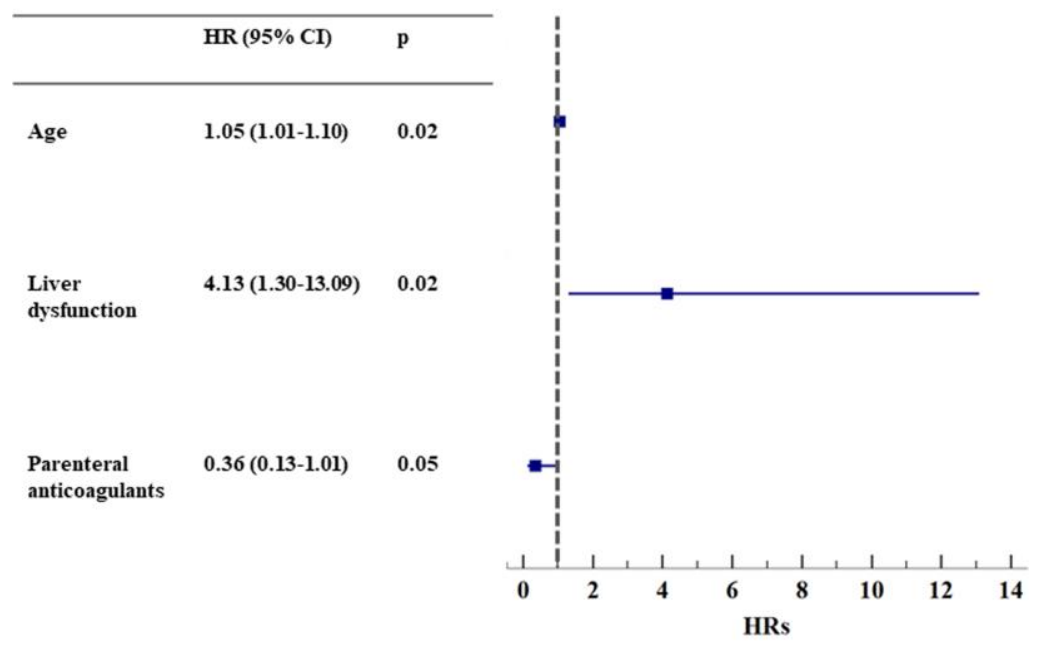

D

\begin{tabular}{lll}
\multicolumn{1}{c}{ Death } & & \\
\hline & HR $(95 \% \mathrm{CI})$ & $\mathrm{p}$ \\
\hline Age & $1.03(1.01-1.05)$ & 0.01 \\
& & \\
Decreased lymphocyte & $1.21(1.16-1.27)$ & $<0.001$ \\
& & \\
Coronary artery disease & $2.35(1.06-5.19)$ & 0.03 \\
& & \\
$\begin{array}{l}\text { Obstructive sleep apnea } \\
\text { syndrome }\end{array}$ & $3.57(0.99-12.87)$ & 0.05 \\
& & \\
Oral anticoagulants & $0.15(0.05-0.49)$ & 0.002
\end{tabular}

E

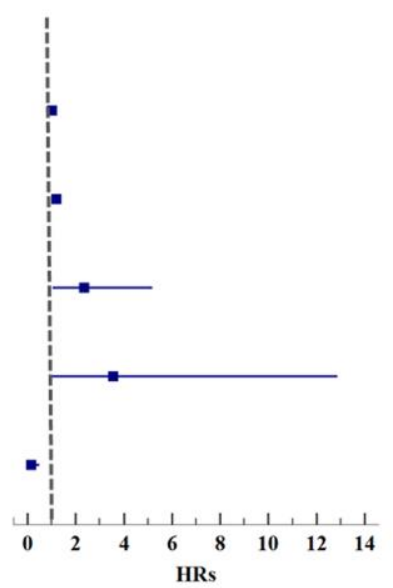

Composite outcomes of thromboembolism, bleeding events, and death

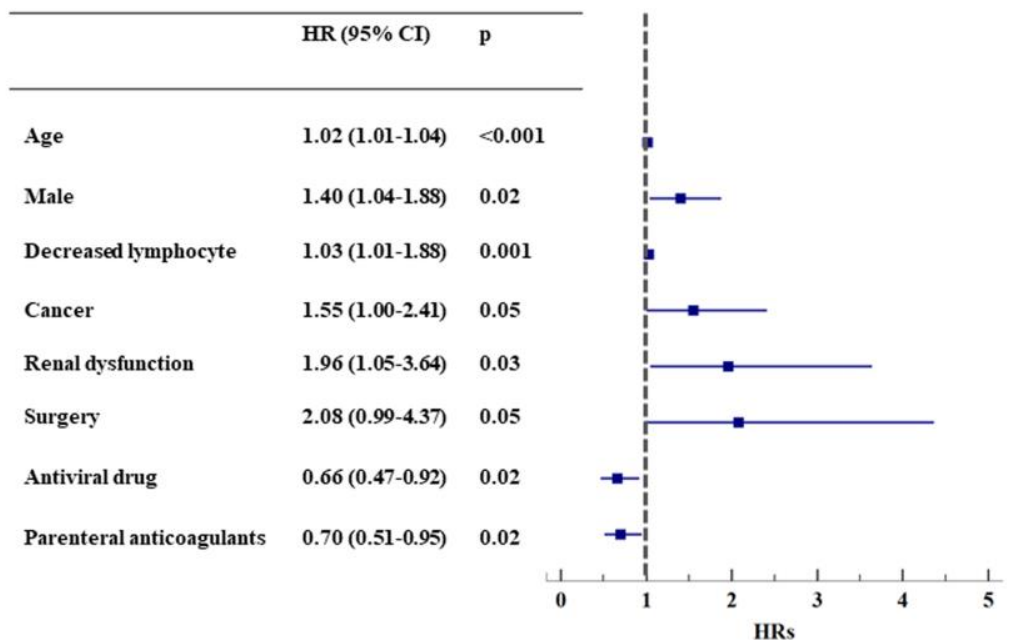

Figure 1. Hazard ratios of clinical events, adjusting for baseline risk factors. (A) Thromboembolism ( $n=82$ ); (B) Major bleeding $(n=113)$; (C) Thromboembolism and bleeding events ( $n=25)$; (D) Death $(n=91)$; (E) Composite outcomes of thromboembolism, bleeding events, and death $(n=235)$. *HR: hazard ratio. Cl: confidential interval. 
Liver dysfunction (HR 4.13, 1.30-13.1, $\mathrm{p}=0.02$ ) was an independent risk factor for patients who sustained both thromboembolism and bleeding events (Figure 1C and Supplementary Table 3). Oral anticoagulants reduced the risk for death (HR 0.15, 0.05-0.49, p=0.002, Figure 1D and Supplementary Table 2C).

After adjustment, parenteral anticoagulant use had a borderline effect on both thromboembolism and bleeding events (HR 0.36, 0.13-1.01, p=0.053, Figure $1 \mathrm{C}$ and Supplementary Table 3) and significantly reduced the risk for the composite outcome of thromboembolism, bleeding events and death (HR 0.70, 0.51-0.95, p=0.02, Figure 1E and Supplementary Table 2D). Other independent predictors of the composite outcome were age, male sex, low lymphocyte count, cancer, renal dysfunction and surgery (Figure 1E and Supplementary Table 2D).

\section{Subgroup analyses}

The subgroups of patients with systemic and venous thromboembolism were analyzed separately. In the multivariate analysis, age (HR 1.07, 1.03-1.11, $\mathrm{p}<0.001$ ), AF rhythm (HR 3.16, 1.06-9.46, p=0.04) and increased respiratory rate $(\mathrm{HR} 1.08,1.01-1.15, \mathrm{p}=0.025)$ were independent risk factors for systemic thromboembolism, but antiviral drugs reduced this risk (HR 0.34, 0.15-0.77, $\mathrm{p}=0.01$, Figure $2 \mathrm{~A}$ and Supplementary Table 4A). Of

A

\begin{tabular}{|c|c|c|}
\hline & HR $(95 \% \mathrm{CI})$ & $\mathbf{p}$ \\
\hline Age & 1.07 & $<0.001$ \\
\hline $\begin{array}{l}\text { Respiratory } \\
\text { rate }\end{array}$ & 1.08 & 0.03 \\
\hline $\begin{array}{l}\text { AF/irregular } \\
\text { rhythm }\end{array}$ & $3.16(1.06-9.46)$ & 0.04 \\
\hline Antiviral drug & $0.34(0.15-0.77)$ & 0.01 \\
\hline
\end{tabular}

B

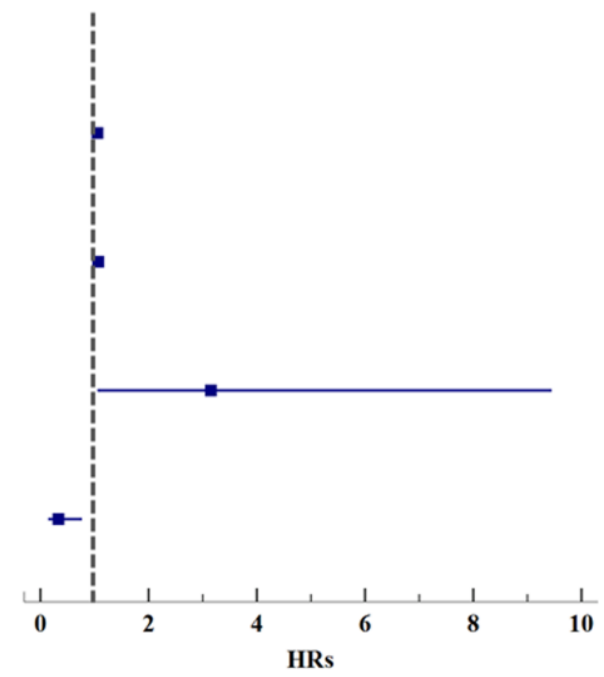

Venous thromboembolism

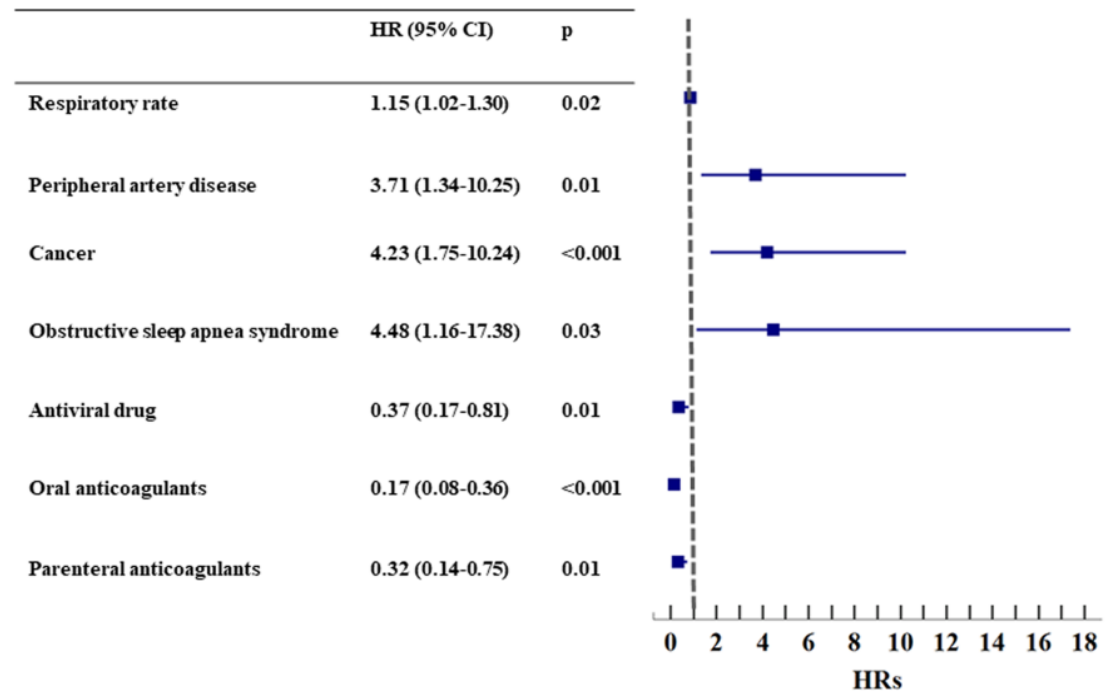

Figure 2. Subgroup analysis for systemic and venous thromboembolism. (A) Systemic thromboembolism ( $n=37)$; (B) Venous thromboembolism ( $n=45)$. * AF: atrial fibrillation. HR: hazard ratio. Cl: confidential interval. 
these patients with systemic thromboembolism, only $5(13.5 \%)$ received oral anticoagulants, and $16(43.2 \%)$ received parenteral anticoagulants (Supplementary Table 5).

The risk of venous thromboembolism was increased with peripheral artery disease, cancer, obstructive sleep apnea syndrome and increased respiratory rate (all $\mathrm{p}<0.05)$ but was reduced by the use of antiviral drugs, oral anticoagulants and parenteral anticoagulants (all $\mathrm{p}<0.01$, Figure 2B and Supplementary Table 4B). There were 25 $(55.6 \%)$ patients on OACs and $33(73.3 \%)$ taking parenteral anticoagulants (Supplementary Table 5).

\section{DISCUSSION}

In this series of COVID-19 patients, our principal findings are as follows: i) thromboembolic, major bleeding and mortality risks were high, with crude in-hospital rates of $7.3 \%, 11.4 \%$ and $8.1 \%$, respectively; ii) age was an independent risk factor for all clinical events, liver dysfunction predicted both thromboembolism and bleeding events, whereas low lymphocyte and surgery were associated with major bleeding; iii) both oral and parenteral anticoagulants reduced the risk for thromboembolism; specifically, parenteral anticoagulants reduced the risk for the composite outcome of thromboembolism, major bleeding and death; and iv) subgroup analysis showed that $\mathrm{AF}$ rhythm increased the risk for systemic thromboembolism.

In several small studies, the incidences of venous thromboembolism (deep vein thrombosis, pulmonary embolism) were reported in $25 \%$ to $31 \%$ of critically ill COVID-19 patients in the intensive care unit [8, 9]. Excessive inflammation has been suggested as one of the main drivers of blood coagulation activation in severely ill patients [10]. In addition to the COVID-19 infection itself, several comorbidities, such as hypertension, AF/irregular rhythm, heart failure, peripheral artery disease, cancer, obstructive sleep apnea syndrome and renal dysfunction, may contribute to thromboembolic risk, even in mild or moderate COVID19 patients. Ischemic stroke was also common, second to venous thromboembolism, suggesting that any thromboprophylaxis approach should aim to prevent both systemic and venous thromboembolic events, even for mild or moderately ill COVID-19 patients.

We are unaware of reported major bleeding outcomes in large cohorts of patients with COVID-19. In the present study, we observed that the rate of bleeding events was $11.4 \%$, which was associated with the severity of COVID-19 itself and any surgery/invasive procedure. Multiorgan dysfunction could be caused by severe
COVID-19 infection, and liver dysfunction was independently associated with both thromboembolic and bleeding risks. Impaired liver synthetic function of coagulation factors has been reported in patients with COVID-19 [13].

The present study demonstrates that the use of both oral (94\% on nonvitamin K antagonist oral anticoagulants) and parenteral anticoagulants was associated with reduced thromboembolism over a mean follow-up of 21 days as well as a reduced risk for death. When taking the composite outcome of thromboembolism, major bleeding and death into consideration, the use of parenteral anticoagulants showed a significant beneficial effect.

In addition, subgroup analyses demonstrated that $\mathrm{AF}$ rhythm independently increased the risk for systemic thromboembolism by threefold. There are reports that $17 \%-44 \%$ of COVID-19 patients suffer from cardiac arrhythmias (commonly AF) [14]. Indeed, inflammation initiates and perpetuates AF and AF-related thrombosis [15]. Our study emphasizes that in patients with COVID-19, detection and awareness of AF and anticoagulation should be considered.

\section{Limitations}

There were several limitations in this study. First, the low rates of confirmed thromboembolism may reflect medical resource limitations, for example, CT scans, especially in the early stages of the COVID-19 outbreak in China. Second, we used electronic medical records in the present study, but the details depended on the thoroughness of the data collection of the risk factors and clinical events. Finally, neither the dosages and duration of LMWH nor the doses of NOACs were formally evaluated.

\section{CONCLUSIONS}

Patients with COVID-19 were at high risk for thromboembolic and bleeding events as well as mortality. Anticoagulant use, especially parenteral anticoagulants, significantly reduced the risk for composite outcomes of thromboembolism, bleeding events and death. The presence of $\mathrm{AF}$ was a contributor to systemic thromboembolism in COVID-19 patients.

\section{MATERIALS AND METHODS}

Patients with COVID-19 admitted to Union Hospital, Wuhan, Hubei, China between January 08, 2020 and April 7, 2020 were included in the study. For this study, we used the electronic medical records database, which recorded the patient's medical history, therapeutic 
procedure(s), and laboratory data, which were related to clinical outcomes and mortality. All the data were first collected and by a group of physicians, then data were independently reviewed and validated by a group of physicians. The medical ethics committee of Tongji Medical College, Huazhong University of Science and Technology approved the present study (Approval No. 2020-S068).

\section{Study population}

The inclusion criteria were patients with a confirmed diagnosis of COVID-19. The diagnosis of COVID-19 was made according to the Guidance for Coronavirus Disease 2019 (6th edition) released by the National Health Commission of China [16] and confirmed by clinical medical history, nucleic acid testing, and CT scan. Rates of thromboembolism, major bleeding events, and all-cause death were recorded. Exclusion criteria included patients with incomplete medical records, therapeutic procedures, or laboratory data. Over the study period, a total of 1,132 patients with confirmed COVID-19 were selected, and after excluding 7 patients with incomplete medical records, we identified 1,125 patients for the final study analysis. We recorded data on the severity of COVID-19 infection, comorbidities, surgery, drug therapies, and use of antithrombotic drugs. Decreased lymphocyte count and respiratory rate were taken as the indexes of the severity of COVID-19 infection [2, 17-19]. Patient comorbidities, including hypertension, diabetes mellitus, lipid disorders, coronary artery disease, cancer, peripheral artery disease, heart failure, hypertrophic cardiomyopathy, obstructive sleep apnea syndrome, and hyperthyroidism, etc. were collected from electronic medical records based on the diagnostic criteria of their retrospective guidelines. Atrial fibrillation (AF) was defined as the diagnosis of AF irregular rhythm in the physical examination recorded in electronic medical records. Liver dysfunction was defined by serum alanine aminotransferase, aspartate transaminase, or alkaline phosphatase levels $>3 \mathrm{x}$ the upper limit of normal or known liver disease. Renal dysfunction was defined by serum creatinine $\geq 200 \mu \mathrm{mol} / \mathrm{l}(2.26$ $\mathrm{mg} / \mathrm{dL}$ ). Lipid disorder was defined as fasting total cholesterol $>240 \mathrm{mg} / \mathrm{dl}(>6.2 \mathrm{mmol} / \mathrm{l})$ or low-density lipoprotein cholesterol $>160 \mathrm{mg} / \mathrm{dl}(>4.1 \mathrm{mmol} / \mathrm{l})$ or treatment with any lipid-lowering drug. Bleeding diathesis was defined as hemoglobin $(\mathrm{Hg})<80 \mathrm{~g} / \mathrm{L}$ or platelet (PLT) count $<50 \times 10^{\wedge} 9 / \mathrm{L}$ on admission. Information on surgery was collected from inpatient medical records. The use of antiviral drugs, antibiotics, immunomodulators, glucocorticoid drugs, and Chinese herbs were recorded, as were oral anticoagulants, parenteral anticoagulants (heparin, LMWH), and antiplatelet drugs.

\section{Outcomes}

Thromboembolism, major bleeding events, and death in the hospital were taken as the outcomes. Thromboembolism included systemic (ischemic stroke) and venous thromboembolism (deep vein thromboembolism and pulmonary embolism). Major bleeding events included intracranial and extracranial hemorrhage, a drop in $\mathrm{Hb} \geq 2 \mathrm{~g} / \mathrm{L}$, or the requirement of red blood cell transfusion $\geq 2$ units. All clinical events were diagnosed by hospital specialists and recorded in the electronic medical records.

\section{Statistical analysis}

Continuous variables were tested for normality by the Kolmogorov-Smirnov test. Those with a normal distribution are presented as the mean (standard deviation, SD). The rates of thromboembolism, major bleeding events, and deaths were calculated.

Univariate analysis was used to analyze underlying risk factors associated with thromboembolism, major bleeding, and death. Multivariable Cox proportional hazards models were used to analyze risk factors associated with clinical events after adjusting for underlying risk factors. We adjusted thromboembolic and bleeding outcomes for potential confounders, including the severity of COVID-19 (decreased lymphocyte count and respiratory rate), related drugs (antiviral drugs, immunomodulators, and Chinese herbs), comorbidities, surgery, and antithrombotic drugs (oral anticoagulants, parenteral anticoagulants, and antiplatelets) (Supplementary Figure 1).

Independent risk factors for the composite of "thromboembolism and bleeding" and the composite outcome of "thromboembolism, bleeding events, and death" were determined. Hazard ratios (HRs, i.e., hazard of intervention to control) and 95\% confidence intervals (CIs) were estimated. Next, the impact of anticoagulants (oral and parenteral) on thromboembolism, major bleeding, and death was studied using Cox proportional hazards models after adjustment for 19 clinical factors: age, male sex, decreased lymphocyte count, respiratory rate, hypertension, coronary artery disease, AF/irregular rhythm, heart failure, diabetes mellitus, peripheral artery disease, cancer, obstructive sleep apnea syndrome, liver dysfunction, renal dysfunction, surgical procedures, and drug therapies (antiviral drugs, immunomodulators, Chinese herbs, and antiplatelet drugs).

Subgroup analysis was carried out for systemic and venous thromboembolism. A two-sided $\mathrm{p}$-value $<0.05$ 
was considered statistically significant. The statistical analysis was performed using IBM SPSS Statistics, version 22.0 (SPSS Inc).

\section{AUTHOR CONTRIBUTIONS}

Jing Xiong and Yutao Guo conceived the study and provided financial support. Wencheng Li designed the study and collected the data. Zhifeng Xu summarized and analyzed the data. Huiling Xiang was involved in data interpretation. Wencheng $\mathrm{Li}$ drafted the manuscript. Chun Zhang revised the manuscript.

\section{ACKNOWLEDGMENTS}

The authors would like to thank Li Weixin and Zhang Xin, who worked as the Mobile Atrial Fibrillation Application Telecare team, Atrial Fibrillation Center, Chinese PLA General Hospital, for the data extraction and follow-up of the patients.

\section{CONFLICTS OF INTEREST}

The authors declare that they have no conflicts of interest.

\section{FUNDING}

This research project was funded by the National Natural Science Foundation of China (No. 8147413) and National Natural Science Foundation of China (No. 81770736).

\section{REFERENCES}

1. WHO. Coronavirus Disease 2019 (COVID-19) Situation Dashboard. 2020.

2. Huang $C$, Wang $Y$, Li $X$, Ren L, Zhao J, Hu Y, Zhang L, Fan G, Xu J, Gu X, Cheng Z, Yu T, Xia J, et al. Clinical features of patients infected with 2019 novel coronavirus in Wuhan, China. Lancet. 2020; 395:497-506. https://doi.org/10.1016/S0140-6736(20)30183-5 PMID:31986264

3. Zhou F, Yu T, Du R, Fan G, Liu Y, Liu Z, Xiang J, Wang Y, Song B, Gu X, Guan L, Wei Y, Li H, et al. Clinical course and risk factors for mortality of adult inpatients with COVID-19 in Wuhan, China: a retrospective cohort study. Lancet. 2020; 395:1054-62. https://doi.org/10.1016/S0140-6736(20)30566-3 PMID:32171076

4. Lippi G, Plebani M, Henry BM. Thrombocytopenia is associated with severe coronavirus disease 2019 (COVID-19) infections: A meta-analysis. Clin Chim Acta. 2020; 506:145-48. https://doi.org/10.1016/i.cca.2020.03.022 PMID:32178975

5. Yang X, Yu Y, Xu J, Shu H, Xia J, Liu H, Wu Y, Zhang L, Yu $Z$, Fang $M, Y u T$, Wang $Y$, Pan $S$, et al. Clinical course and outcomes of critically ill patients with SARS-CoV-2 pneumonia in Wuhan, China: a single-centered, retrospective, observational study. Lancet Respir Med. 2020; 8:475-81. https://doi.org/10.1016/S2213-2600(20)30079-5 PMID:32105632

6. Gao Y, Li T, Han M, Li X, Wu D, Xu Y, Zhu Y, Liu Y, Wang $X$, Wang L. Diagnostic utility of clinical laboratory data determinations for patients with the severe COVID-19. J Med Virol. 2020; 92:791-96. https://doi.org/10.1002/jmv.25770 PMID:32181911

7. Zhang $\mathrm{Y}$, Xiao $\mathrm{M}$, Zhang $\mathrm{S}$, Xia $\mathrm{P}$, Cao $\mathrm{W}$, Jiang $\mathrm{W}$, Chen $H$, Ding $X$, Zhao $H$, Zhang $H$, Wang $C$, Zhao J, Sun $X$, et al. Coagulopathy and Antiphospholipid Antibodies in Patients with Covid-19. N Engl J Med. 2020; 382:e38. https://doi.org/10.1056/NEJMc2007575 PMID:32268022

8. Cui S, Chen S, Li X, Liu S, Wang F. Prevalence of venous thromboembolism in patients with severe novel coronavirus pneumonia. J Thromb Haemost. 2020; 18:1421-24.

https://doi.org/10.1111/jth.14830

PMID:32271988

9. Klok FA, Kruip MJ, van der Meer NJ, Arbous MS, Gommers DA, Kant KM, Kaptein FH, van Paassen J, Stals MA, Huisman MV, Endeman $H$. Incidence of thrombotic complications in critically ill ICU patients with COVID-19. Thromb Res. 2020; 191:145-47. https://doi.org/10.1016/j.thromres.2020.04.013 PMID:32291094

10. Bikdeli B, Madhavan MV, Jimenez D, Chuich T, Dreyfus I, Driggin E, Nigoghossian C, Ageno W, Madjid M, Guo Y, Tang LV, Hu Y, Giri J, et al, and Global COVID-19 Thrombosis Collaborative Group, Endorsed by the ISTH, NATF, ESVM, and the IUA, Supported by the ESC Working Group on Pulmonary Circulation and Right Ventricular Function. COVID-19 and thrombotic or thromboembolic disease: implications for prevention, antithrombotic therapy, and follow-up: JACC state-ofthe-art review. J Am Coll Cardiol. 2020; 75:2950-73.

https://doi.org/10.1016/i.jacc.2020.04.031 PMID:32311448

11. Yin S, Huang M, Li D, Tang N. Difference of coagulation features between severe pneumonia induced by SARSCoV2 and non-SARS-CoV2. J Thromb Thrombolysis. 2020. [Epub ahead of print]. https://doi.org/10.1007/s11239-020-02105-8 PMID:32246317 
12. AIFA. https://www.aifa.gov.it/documents/20142/ 1123276/Eparine Basso Peso Molecolare 11.04.20 20.pdf/e30686fb-3f5e-32c9-7c5c-951cc40872f7.

13. Zhang $Y$, Zheng L, Liu L, Zhao M, Xiao J, Zhao Q. Liver impairment in COVID-19 patients: A retrospective analysis of 115 cases from a single centre in Wuhan city, China. Liver Int. 2020; 40:2095-103.

https://doi.org/10.1111/liv.14455

PMID:32239796

14. Wang D, Hu B, Hu C, Zhu F, Liu X, Zhang J, Wang B, Xiang $\mathrm{H}$, Cheng Z, Xiong $\mathrm{Y}$, Zhao $\mathrm{Y}$, Li Y, Wang X, Peng Z. Clinical characteristics of 138 hospitalized patients with 2019 novel coronavirus-infected pneumonia in Wuhan, China. JAMA. 2020; 323:1061-69. https://doi.org/10.1001/jama.2020.1585 PMID:32031570

15. Guo Y, Lip GY, Apostolakis S. Inflammation in atrial fibrillation. J Am Coll Cardiol. 2012; 60:2263-70.

https://doi.org/10.1016/j.jacc.2012.04.063

PMID:23194937
16. Program Ncppac, Chinese tei. New coronavirus pneumonia prevention and control program (6th ed) (in Chinese). http://www.nhc.gov.cn/yzygj/

17. Frater JL, Zini G, d'Onofrio G, Rogers HJ. COVID-19 and the clinical hematology laboratory. Int J Lab Hematol. 2020 (Suppl 1); 42:11-18.

https://doi.org/10.1111/ijlh.13229

PMID:32311826

18. Lippi G, Plebani M. Laboratory abnormalities in patients with COVID-2019 infection. Clin Chem Lab Med. 2020; 58:1131-34. https://doi.org/10.1515/cclm-2020-0198 PMID: $\underline{32119647}$

19. Wiersinga WJ, Rhodes A, Cheng AC, Peacock SJ, Prescott HC. Pathophysiology, transmission, diagnosis, and treatment of coronavirus disease 2019 (COVID19): a review. JAMA. 2020; 324:782-93. https://doi.org/10.1001/jama.2020.12839 PMID:32648899 


\section{SUPPLEMENTARY MATERIALS}

\section{Supplementary Figure}

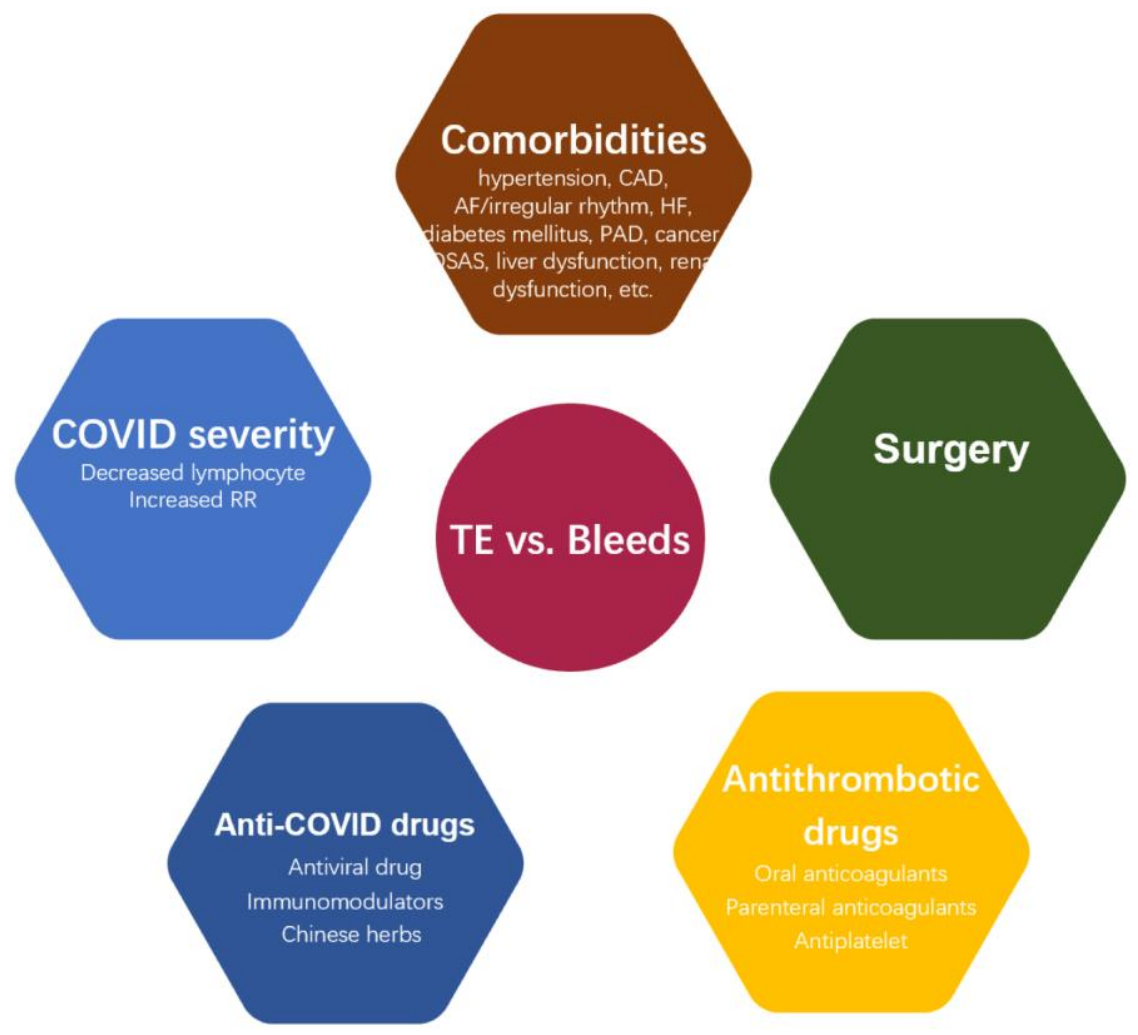

Supplementary Figure 1. The underlying factors in analysis for thromboembolic and bleeding risk in patients with COVID2019. CAD: coronary artery disease. HF: heart failure. PAD: peripheral artery disease. OSAS: Obstructive sleep apnea syndrome. RR: respiratory rate. 


\section{Supplementary Tables}

Supplementary Table 1. Specialties of hospitalised patients when first admitted.

\begin{tabular}{lcc}
\hline & Sites $(\mathbf{n}=\mathbf{1 1 2 5})$ & Rate, \\
\hline Surgery & 491 & $43.6 \%$ \\
Obstetrics and Gynaecology & 141 & $12.5 \%$ \\
Cardiology & 91 & $8.1 \%$ \\
Ear/Nose/Throat & 90 & $8.0 \%$ \\
Respiratory & 74 & $6.6 \%$ \\
Haematology & 71 & $6.3 \%$ \\
Neurology & 57 & $5.1 \%$ \\
Ophthalmology & 54 & $4.8 \%$ \\
Gastroenterology & 31 & $2.8 \%$ \\
Intensive care unit & 1 & $0.1 \%$ \\
Others & 24 & $2.1 \%$ \\
\hline
\end{tabular}

Supplementary Table 2. Hazard ratios for clinical events.

A. Thromboembolism ( $n=82)$.

\begin{tabular}{|c|c|c|c|c|c|c|c|c|}
\hline & \multicolumn{4}{|c|}{ Univariate analysis } & \multicolumn{4}{|c|}{ Multivariate analysis } \\
\hline & \multirow{2}{*}{ HR } & \multicolumn{2}{|c|}{$95 \% \mathrm{CI}$} & \multirow{2}{*}{$\mathbf{P}$} & \multirow{2}{*}{ HR } & \multicolumn{2}{|c|}{$95 \% \mathrm{CI}$} & \multirow{2}{*}{$\mathbf{P}$} \\
\hline & & Lower limit & Higher limit & & & Lower limit & Higher limit & \\
\hline Age & 1.06 & 1.04 & 1.08 & $<0.001$ & 1.03 & 1.01 & 1.06 & 0.005 \\
\hline Male & 0.85 & 0.55 & 1.32 & 0.46 & 0.88 & 0.53 & 1.48 & 0.64 \\
\hline Decreased lymphocyte & 1.00 & 0.98 & 1.01 & 0.81 & 1.01 & 1.00 & 1.01 & 0.25 \\
\hline Respiratory rate & 0.98 & 0.92 & 1.04 & 0.47 & 1.01 & 0.95 & 1.08 & 0.78 \\
\hline Hypertension & 2.86 & 1.82 & 4.48 & $<0.001$ & 1.62 & 0.95 & 2.77 & 0.08 \\
\hline $\begin{array}{l}\text { Coronary artery } \\
\text { disease }\end{array}$ & 1.47 & 0.79 & 2.74 & 0.22 & 0.51 & 0.21 & 1.21 & 0.12 \\
\hline AF/irregular rhythm & 2.87 & 1.51 & 5.43 & 0.001 & 1.90 & 0.85 & 4.27 & 0.12 \\
\hline Heart failure & 3.67 & 1.76 & 7.66 & 0.001 & 1.92 & 0.73 & 5.03 & 0.18 \\
\hline Diabetes mellitus & 0.96 & 0.55 & 1.67 & 0.89 & 0.56 & 0.27 & 1.13 & 0.11 \\
\hline $\begin{array}{l}\text { Peripheral artery } \\
\text { disease }\end{array}$ & 2.90 & 1.49 & 5.67 & 0.002 & 2.10 & 0.92 & 4.80 & 0.08 \\
\hline Cancer & 2.84 & 1.54 & 5.26 & 0.001 & 1.94 & 0.94 & 4.02 & 0.07 \\
\hline $\begin{array}{l}\text { Obstructive sleep } \\
\text { apnea syndrome }\end{array}$ & 3.75 & 1.37 & 10.28 & 0.01 & 2.06 & 0.69 & 6.11 & 0.19 \\
\hline Liver dysfunction & 1.58 & 0.73 & 3.43 & 0.25 & 1.41 & 0.55 & 3.61 & 0.47 \\
\hline Renal dysfunction & 2.88 & 1.05 & 7.90 & 0.04 & 1.73 & 0.54 & 5.56 & 0.35 \\
\hline Surgery & 1.82 & 0.57 & 5.79 & 0.31 & 2.17 & 0.60 & 7.88 & 0.24 \\
\hline Antiviral drug & 0.28 & 0.18 & 0.44 & $<0.001$ & 0.32 & 0.19 & 0.55 & $<0.001$ \\
\hline Immunomodulator & 0.47 & 0.30 & 0.73 & 0.001 & 0.62 & 0.37 & 1.04 & 0.07 \\
\hline Chinese herbs & 1.39 & 0.85 & 2.26 & 0.19 & 1.22 & 0.68 & 2.19 & 0.52 \\
\hline Oral anticoagulants & 0.24 & 0.15 & 0.38 & $<0.001$ & 0.32 & 0.19 & 0.53 & $<0.001$ \\
\hline $\begin{array}{l}\text { Parenteral } \\
\text { anticoagulants }\end{array}$ & 0.23 & 0.14 & 0.37 & $<0.001$ & 0.39 & 0.22 & 0.70 & 0.001 \\
\hline Antiplatelet & 0.45 & 0.27 & 0.75 & 0.002 & 1.63 & 0.80 & 3.31 & 0.18 \\
\hline
\end{tabular}

* AF: atrial fibrillation. HR: hazard ratio. $\mathrm{Cl}$ : confidence interval. 


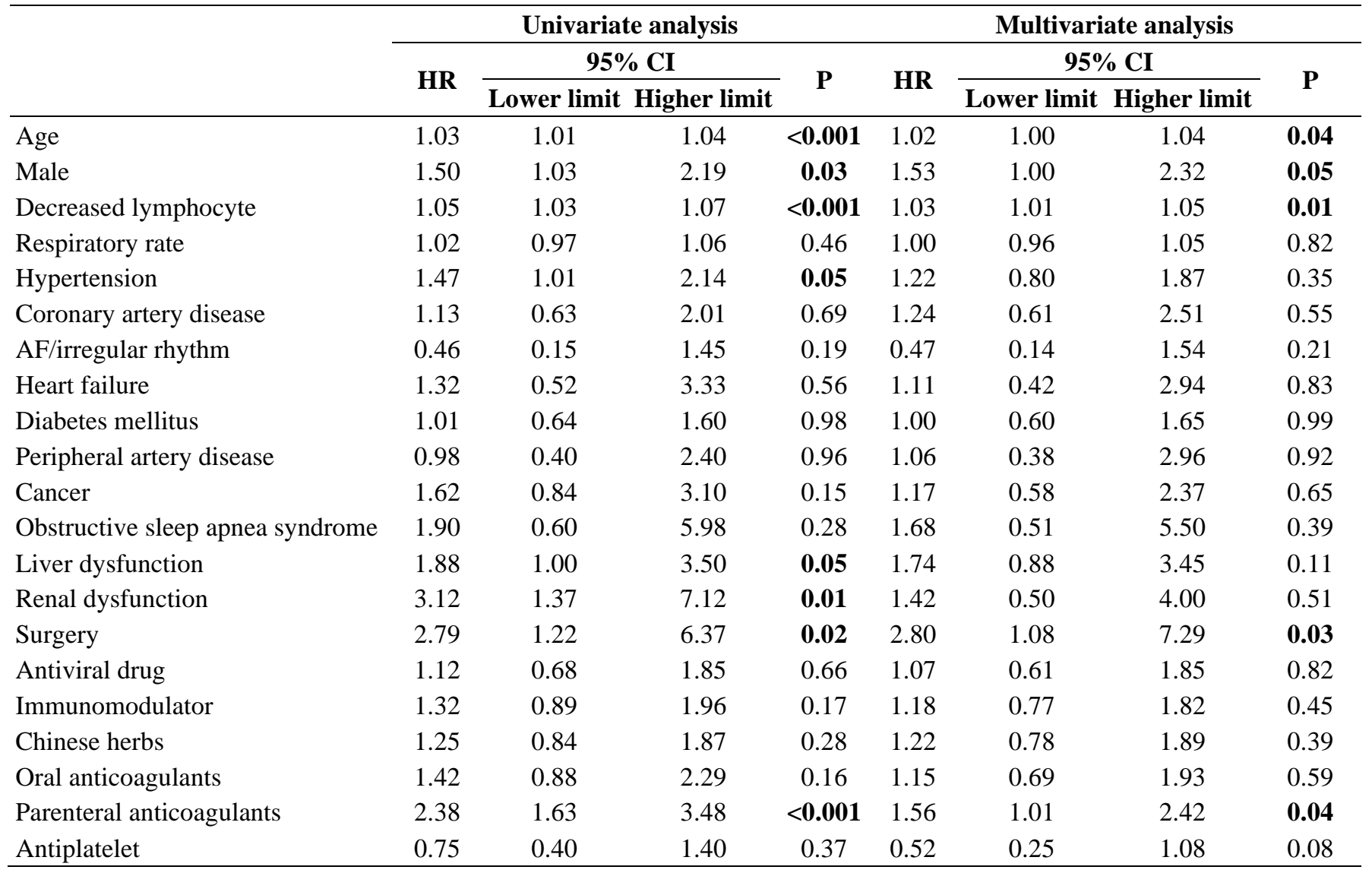

* AF: atrial fibrillation. HR: hazard ratio. Cl: confidence interval.

C. Death ( $n=91)$.

\begin{tabular}{|c|c|c|c|c|c|c|c|c|}
\hline & \multicolumn{4}{|c|}{ Univariate analysis } & \multicolumn{4}{|c|}{ Multivariate analysis } \\
\hline & \multirow{2}{*}{ HR } & \multicolumn{2}{|c|}{$95 \% \mathrm{CI}$} & \multirow{2}{*}{$\mathbf{P}$} & \multirow{2}{*}{ HR } & \multicolumn{2}{|c|}{$95 \% \mathrm{CI}$} & \multirow{2}{*}{$\mathbf{P}$} \\
\hline & & Lower limit & Higher limit & & & Lower limit & Higher limit & \\
\hline Age & 1.05 & 1.04 & 1.07 & $<0.001$ & 1.03 & 1.01 & 1.05 & 0.01 \\
\hline Male & 1.68 & 1.10 & 2.57 & 0.02 & 1.16 & 0.69 & 1.97 & 0.57 \\
\hline Decreased lymphocyte & 1.21 & 1.16 & 1.26 & $<0.001$ & 1.21 & 1.16 & 1.27 & $<0.001$ \\
\hline Respiratory rate & 1.04 & 1.00 & 1.09 & 0.04 & 1.00 & 0.96 & 1.04 & 0.96 \\
\hline Hypertension & 1.54 & 1.01 & 2.33 & 0.04 & 1.00 & 0.59 & 1.69 & 0.99 \\
\hline Coronary artery disease & 1.74 & 0.98 & 3.07 & 0.06 & 2.35 & 1.06 & 5.19 & 0.03 \\
\hline AF/irregular rhythm & 0.76 & 0.28 & 2.07 & 0.59 & 0.73 & 0.19 & 2.75 & 0.64 \\
\hline Heart failure & 3.09 & 1.43 & 6.68 & 0.004 & 1.28 & 0.45 & 3.63 & 0.65 \\
\hline Diabetes mellitus & 1.85 & 1.18 & 2.90 & 0.01 & 1.26 & 0.72 & 2.20 & 0.43 \\
\hline Peripheral artery disease & 0.87 & 0.28 & 2.77 & 0.82 & 0.76 & 0.18 & 3.25 & 0.71 \\
\hline Cancer & 1.81 & 0.91 & 3.60 & 0.09 & 1.43 & 0.67 & 3.07 & 0.36 \\
\hline $\begin{array}{l}\text { Obstructive sleep apnea } \\
\text { syndrome }\end{array}$ & 2.06 & 0.65 & 6.52 & 0.22 & 3.57 & 0.99 & 12.87 & 0.05 \\
\hline Liver dysfunction & 2.50 & 1.36 & 4.59 & 0.003 & 1.45 & 0.70 & 3.01 & 0.32 \\
\hline Renal dysfunction & 6.40 & 3.40 & 12.01 & $<0.001$ & 1.74 & 0.75 & 4.05 & 0.20 \\
\hline Surgery & 0.40 & 0.06 & 2.84 & 0.36 & 0.91 & 0.12 & 6.98 & 0.93 \\
\hline Antiviral drug & 1.11 & 0.68 & 1.82 & 0.67 & 1.76 & 0.89 & 3.51 & 0.11 \\
\hline Immunomodulator & 1.32 & 0.86 & 2.02 & 0.21 & 1.00 & 0.57 & 1.74 & 1.00 \\
\hline
\end{tabular}




\begin{tabular}{lcccccccc} 
Chinese herbs & 1.43 & 0.91 & 2.23 & 0.12 & 0.92 & 0.54 & 1.57 & 0.76 \\
Oral anticoagulants & 0.31 & 0.10 & 0.98 & $\mathbf{0 . 0 5}$ & 0.15 & 0.05 & 0.49 & $\mathbf{0 . 0 0 2}$ \\
Parenteral anticoagulants & 0.60 & 0.32 & 0.77 & $\mathbf{0 . 0 0 2}$ & 0.82 & 0.48 & 1.39 & 0.47 \\
Antiplatelet & 0.59 & 0.26 & 1.35 & 0.21 & 0.49 & 0.18 & 1.32 & 0.16 \\
\hline
\end{tabular}

* AF: atrial fibrillation. HR: hazard ratio. Cl: confidence interval.

D. Composite outcomes of thromboembolism, bleeding events, and death $(n=235)$.

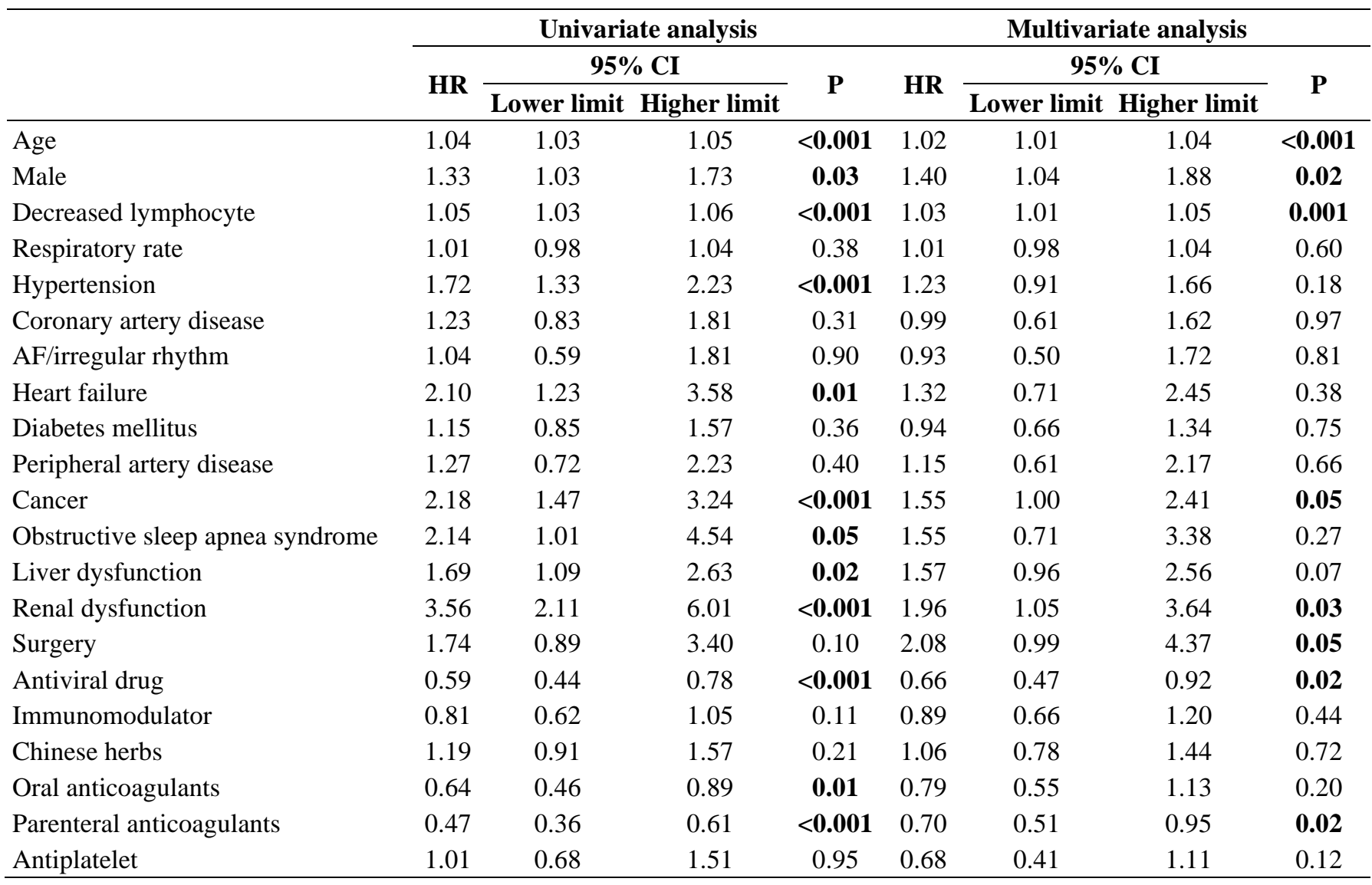

* AF: atrial fibrillation. HR: hazard ratio. Cl: confidence interval. 
Supplementary Table 3. Hazard ratios for composite of thromboembolism and bleeding events ( $n=25)$.

\begin{tabular}{lcccc}
\hline & Hazard ratios & \multicolumn{2}{c}{ Confidence interval } & \multirow{2}{*}{ P } \\
\cline { 3 - 4 } & & Low & High & \\
\hline Age & 1.05 & 1.01 & 1.10 & $\mathbf{0 . 0 2}$ \\
Male & 1.14 & 0.46 & 2.78 & 0.78 \\
Decreased lymphocyte & 0.98 & 0.94 & 1.03 & 0.47 \\
Respiratory rate & 0.91 & 0.79 & 1.05 & 0.18 \\
Hypertension & 1.17 & 0.46 & 2.97 & 0.75 \\
Coronary artery disease & 0.43 & 0.09 & 2.13 & 0.30 \\
AF/irregular rhythm & 1.23 & 0.26 & 5.74 & 0.79 \\
Heart failure & 2.29 & 0.48 & 10.85 & 0.30 \\
Diabetes mellitus & 0.66 & 0.20 & 2.20 & 0.50 \\
Peripheral artery disease & 1.91 & 0.41 & 8.80 & 0.41 \\
Cancer & 0.85 & 0.18 & 4.11 & 0.84 \\
Obstructive sleep apnea syndrome & 3.63 & 0.67 & 19.53 & 0.13 \\
Liver dysfunction & 4.13 & 1.30 & 13.09 & $\mathbf{0 . 0 2}$ \\
Renal dysfunction & 2.34 & 0.36 & 15.27 & 0.37 \\
Antiviral drug & 0.46 & 0.16 & 1.38 & 0.17 \\
Immunomodulator & 1.03 & 0.39 & 2.71 & 0.95 \\
Chinese herbs & 2.06 & 0.62 & 6.84 & 0.24 \\
Oral anticoagulants & 1.84 & 0.71 & 4.78 & 0.21 \\
Parenteral anticoagulants & 0.36 & 0.13 & 1.01 & $\mathbf{0 . 0 5}$ \\
Antiplatelet & 1.21 & 0.36 & 4.04 & 0.76 \\
\hline
\end{tabular}

${ }^{*}$ AF: atrial fibrillation. 
Supplementary Table 4. Subgroup analysis.

A. Systemic thromboembolism ( $n=37)$.

\begin{tabular}{lcccc}
\hline & Hazard ratios & \multicolumn{2}{c}{ Confidence interval } & \multirow{2}{*}{ P } \\
\cline { 3 - 4 } & & Low & High & \\
\hline Age & 1.07 & 1.03 & 1.11 & $<\mathbf{0 0 1}$ \\
Male & 0.89 & 0.41 & 1.95 & 0.77 \\
Decreased lymphocyte & 1.00 & 0.96 & 1.04 & 0.87 \\
Respiratory rate & 1.08 & 1.01 & 1.15 & $\mathbf{0 . 0 3}$ \\
Hypertension & 1.97 & 0.89 & 4.33 & 0.09 \\
Coronary artery disease & 0.39 & 0.10 & 1.48 & 0.17 \\
AF/irregular rhythm & 3.16 & 1.06 & 9.46 & $\mathbf{0 . 0 4}$ \\
Heart failure & 0.94 & 0.15 & 5.93 & 0.94 \\
Diabetes mellitus & 0.73 & 0.25 & 2.07 & 0.55 \\
Peripheral artery disease & 1.30 & 0.27 & 6.32 & 0.75 \\
Cancer & 0.24 & 0.03 & 1.91 & 0.18 \\
Obstructive sleep apnea syndrome & 2.86 & 0.61 & 13.42 & 0.18 \\
Liver dysfunction & 0.42 & 0.04 & 3.87 & 0.44 \\
Renal dysfunction & 1.63 & 0.17 & 15.69 & 0.67 \\
Surgery & 3.47 & 0.44 & 27.41 & 0.24 \\
Antiviral drug & 0.34 & 0.15 & 0.77 & $\mathbf{0 . 0 1}$ \\
Immunomodulator & 0.64 & 0.28 & 1.47 & 0.30 \\
Chinese herbs & 1.01 & 0.44 & 2.31 & 0.98 \\
Oral anticoagulants & 0.61 & 0.20 & 1.86 & 0.39 \\
Parenteral anticoagulants & 0.47 & 0.21 & 1.08 & 0.08 \\
Antiplatelet & 1.51 & 0.53 & 4.30 & 0.44 \\
\hline
\end{tabular}

*AF: atrial fibrillation.

B. Venous thromboembolism ( $n=45)$.

\begin{tabular}{lcccc}
\hline & Hazard ratios & \multicolumn{2}{c}{ Confidence interval } & \multirow{2}{*}{ P } \\
\cline { 3 - 4 } & & Low & High & \\
\hline Age & 1.02 & 0.99 & 1.05 & 0.14 \\
Male & 1.13 & 0.54 & 2.36 & 0.74 \\
Decreased lymphocyte & 1.00 & 0.98 & 1.01 & 0.64 \\
Respiratory rate & 1.15 & 1.02 & 1.30 & $\mathbf{0 . 0 2}$ \\
Hypertension & 1.29 & 0.60 & 2.78 & 0.51 \\
Coronary artery disease & 0.86 & 0.26 & 2.85 & 0.80 \\
AF/irregular rhythm & 1.39 & 0.42 & 4.59 & 0.59 \\
Heart failure & 2.73 & 0.79 & 9.49 & 0.11 \\
Diabetes mellitus & 0.45 & 0.16 & 1.30 & 0.14 \\
Peripheral artery disease & 3.71 & 1.34 & 10.25 & $\mathbf{0 . 0 1}$ \\
Cancer & 4.23 & 1.75 & 10.24 & $<\mathbf{0 . 0 0 1}$ \\
Obstructive sleep apnea syndrome & 4.48 & 1.16 & 17.38 & $\mathbf{0 . 0 3}$ \\
Liver dysfunction & 1.69 & 0.47 & 6.12 & 0.42 \\
Renal dysfunction & 1.55 & 0.38 & 6.25 & 0.54 \\
Surgery & 2.16 & 0.39 & 11.94 & 0.38 \\
Antiviral drug & 0.37 & 0.17 & 0.81 & $\mathbf{0 . 0 1}$ \\
Immunomodulator & 0.57 & 0.28 & 1.19 & 0.14 \\
Chinese herbs & 0.96 & 0.41 & 2.25 & 0.92
\end{tabular}


Oral anticoagulants

Parenteral anticoagulants

Antiplatelet

* AF: atrial fibrillation.

$\begin{array}{cccc}0.17 & 0.08 & 0.36 & <\mathbf{0 . 0 0 1} \\ 0.32 & 0.14 & 0.75 & \mathbf{0 . 0 1} \\ 1.45 & 0.50 & 4.20 & 0.50\end{array}$

0.17

0.50

4.20

0.50

Supplementary Table 5. Antithrombotic treatment in patients with venous thromboembolism and systemic thromboembolism.

\begin{tabular}{lcc}
\hline & $\begin{array}{c}\text { Patients with systemic thromboembolism } \\
(\mathbf{n = 3 7 )}\end{array}$ & $\begin{array}{c}\text { Patients with venous thromboembolism } \\
(\mathbf{n = 4 5})\end{array}$ \\
\hline Oral anticoagulants, $\mathrm{n}(\%)$ & $5(13.5)$ & $25(55.6)$ \\
Parenteral anticoagulants, $\mathrm{n}(\%)$ & $16(43.2)$ & $33(73.3)$ \\
Antiplatelet, $\mathrm{n}(\%)$ & $9(24.3)$ & $9(20.0)$ \\
\hline
\end{tabular}

